\title{
Preference Heterogeneity in Monetary Policy Committees*
}

\author{
Alessandro Riboni and Francisco J. Ruge-Murcia \\ Département de sciences économiques, Université de Montréal
}

This short paper employs individual voting records of the Monetary Policy Committee (MPC) of the Bank of England to study heterogeneity in policy preferences among committee members. The analysis is carried out using a simple generalization of the standard New Keynesian framework that allows members to differ in the weight they give to output compared with inflation stabilization and in their views regarding optimal inflation and natural output. Results indicate that, qualitatively, MPC members are fairly homogeneous in their policy preferences, but there are systematic quantitative differences in their policy reaction functions that are related to the nature of their membership and career background.

JEL Codes: E4, E5, D7.

\section{Introduction}

This short paper uses the individual voting records of the Monetary Policy Committee (MPC) of the Bank of England to study the extent and nature of preference heterogeneity among committee members. Understanding committees is important because many central banks use a committee structure to formulate policy. This is the case, for example, in seventy-nine of the eighty-eight central banks in Fry et al. (2000). At the theoretical level, we use a simple generalization of the standard New Keynesian framework that allows members to differ in the relative weight they attach

${ }^{*}$ Work on this research project was carried out while the second author was Visiting Scholar at the Dutch National Bank. The financial support of the Social Sciences and Humanities Research Council of Canada is gratefully acknowledged. Corresponding author: Francisco J. Ruge-Murcia, Département de sciences économiques, Université de Montréal, C.P. 6128, succursale Centre-ville, Montréal (Québec) H3C 3J7, Canada. 
to output versus inflation stabilization and in their views regarding optimal inflation and natural output. Under the assumption of sincere voting, individual reaction functions are derived and estimated for each member and for the committee as a whole. The model implies that, given the economy parameters and privatesector expectations, committee members agree on their reaction to the expected output gap and demand shocks and disagree on their reaction to expected inflation and supply shocks. In addition, members will differ systematically in their preferred interest rate even if they share the same inflation target and estimate of the natural output rate.

A first snapshot of the MPC voting records reveals that disagreement is frequent at the policy meetings of the Bank of England. In about two thirds of meetings between June 1997 and June 2006, decisions were not unanimous. Summary statistics like those computed, for example, by Gerlach-Kristen (2003) and Spencer (2006) are suggestive of heterogeneous preferences over policy. Both studies conclude that external members appear to have different voting patterns than internal ones, tend to dissent more frequently, and - when they dissent - are more likely to vote for a lower interest rate. These results mirror the ones obtained by the literature on the Federal Open Market Committee (FOMC), which usually finds that Federal Reserve Board members appear to prefer more expansionary policy than the Reserve Bank presidents (see Belden 1989, Gildea 1990, Havrilesky and Schweitzer 1990, and Havrilesky and Gildea 1991). The aforementioned literature uses dissenting votes only and analyzes differences in the voting behavior of the two groups by comparing dissenting frequencies. Tootell (1991, 1999), whose approach is followed here, uses instead all votes and investigates heterogeneity within the FOMC by comparing coefficients of individual policy reaction functions. Contrary to the previous literature, he finds no evidence of a systematic difference in voting patterns between Board members and Bank presidents. Individual reaction functions are also estimated by Chappell, McGregor, and Vermilyea (2005). The literature has also considered other factors that may have an effect on FOMC voting behavior, such as career backgrounds (see Gildea 1990 and Havrilesky and Schweitzer 1990) and regional affiliations. For example, Meade and Sheets (2005) find that regional unemployment rates have a statistically significant 
effect on the voting patterns of Bank presidents and Board members alike.

The main empirical results are the following. First, committee members behave in agreement with economic theory in the sense that (i) they generally favor higher (lower) interest rates when inflation (unemployment) is expected to increase and (ii) the overidentification restrictions of the model are not rejected by the data. Thus, in qualitative terms, MPC members are fairly homogeneous in their policy preferences. Second, the joint hypothesis that individual reaction-function coefficients are equal to those of the committee is rejected by the data. Hence, in quantitative terms, there is heterogeneity in policy reaction functions. Third, this heterogeneity appears to be systematic in that individuals who favor a strong response to expected inflation or unemployment do so regardless of the forecasts horizon. Fourth, systematic heterogeneity appears to be related to the nature of the membership (whether external or internal) and individual career background (whether academia, private sector, or Bank of England). These two characteristics are not independent, because most academics and individuals with privatesector experience are external members. In general, we find that external members react more strongly to unemployment than internal members, but there is no clear pattern regarding their reaction to inflation.

The paper is organized as follows: section 2 describes the model that motivates the empirical specification, section 3 reports empirical results, and section 4 concludes.

\section{The Model}

Consider a monetary policy committee composed of $N$ members. Assume that members have heterogeneous policy preferences in the sense that they may attach different relative weights to output versus inflation stabilization and may have different views regarding the optimal inflation rate and the true natural output level. The payoff of member $n \in\{1,2, \ldots, N\}$ in each period is

$$
U_{n}\left(\pi_{t}, x_{t}\right)=-(1 / 2)\left(\left(\pi_{t}-\pi_{n, t}^{*}\right)^{2}+\alpha_{n}\left(x_{t}-x_{n, t}^{*}\right)^{2}\right),
$$


where $\pi_{t}$ is the inflation rate; $x_{t}$ is an output measure; $\pi_{n, t}^{*}$ and $x_{n, t}^{*}$ are, respectively, the optimal inflation rate and the natural level of $x_{t}$ according to member $n$; and $\alpha_{n}>0$ is the relative weight that member $n$ attaches to output stabilization. Normalizing the inflation weight to one entails no loss of generality. The special case where members agree on a (possibly time-varying) inflation target corresponds to $\pi_{n, t}^{*}=\pi_{t}^{*}$ for all $n$. The difference between member $n$ 's estimate of the natural rate and its true value is assumed to be well approximated by

$$
x_{t}^{*}-x_{n, t}^{*}=\nu_{n, t},
$$

where $\nu_{n, t}$ is an exogenous autocorrelated disturbance with zero mean and constant conditional variance. This formulation allows the special cases where all members share the same estimate of the natural rate when $\nu_{n, t}=\nu_{t}$ for all $n .^{1}$

The behavior of the private sector is summarized by

$$
\begin{aligned}
& x_{t}=x_{t}^{*}-\phi\left(i_{t}-E_{t} \pi_{t+1}\right)+E_{t}\left(x_{t+1}-x_{t+1}^{*}\right)+\varepsilon_{t}, \\
& \pi_{t}=\lambda\left(x_{t}-x_{t}^{*}\right)+\beta E_{t} \pi_{t+1}+\eta_{t},
\end{aligned}
$$

where $i_{t}$ is the nominal interest rate; $\phi, \lambda, \beta>0$ are constant parameters; $E_{t}$ denotes the public's expectations conditional on information available at time $t$; and $\varepsilon_{t}$ and $\eta_{t}$ are exogenous autocorrelated disturbances with zero mean and constant conditional variance. The public is assumed to form expectations rationally, and its information set at time $t$ includes current and previous realizations of all model variables and shocks. Equation (3) is an IS curve and equation (4) is the New Keynesian Phillips curve. The IS curve may be derived from a linearized Euler equation for consumption and the resource constraint (see McCallum and Nelson 1999). The New Keynesian Phillips curve may be derived from the linearized pricing decision of a profit-maximizing monopolistic competitor in a sticky-price environment.

\footnotetext{
${ }^{1}$ It is easy to generalize the model to the case where member $n$ 's estimate of the natural rate differs systematically from its true value by introducing a member-specific constant in equation (2). This generalization does not change the reduced form of the reaction function estimated below, but it changes the structural interpretation of its intercept.
} 
Committee members are assumed to sincerely cast their vote. In each period and under discretion, ${ }^{2}$ the policymaker $n$ computes $x_{t}$ and $\pi_{t}$ to maximize

$$
E_{t} \sum_{\tau=0}^{\infty} \beta^{\tau} U_{n}\left(\pi_{t+\tau}, x_{t+\tau}\right)
$$

subject to the aggregate supply curve and the IS curve. Given the optimal values of $\pi_{t}$ and $x_{t}$, the interest rate preferred by member $n$ is determined by equation (3). Since private-sector expectations are taken as given by policymakers, future inflation and output are not affected by current decisions, and the first-order condition reads

$$
\lambda\left(\pi_{t}-\pi_{n, t}^{*}\right)+\alpha_{n}\left(x_{t}-x_{n, t}^{*}\right)=0 .
$$

Using (5), (2), and the aggregate relations (3) and (4), one can write

$$
\begin{aligned}
i_{n, t}^{*}= & -\left(\frac{\lambda}{\phi\left(\alpha_{n}+\lambda^{2}\right)}\right) \pi_{n, t}^{*}+\left(1+\frac{\lambda \beta}{\phi\left(\alpha_{n}+\lambda^{2}\right)}\right) E_{t} \pi_{t+1} \\
& +\left(\frac{1}{\phi}\right) E_{t}\left(x_{t+1}-x_{t+1}^{*}\right)+\left(\frac{\lambda}{\phi\left(\alpha_{n}+\lambda^{2}\right)}\right) \eta_{t} \\
& +\left(\frac{\alpha_{n}}{\phi\left(\alpha_{n}+\lambda^{2}\right)}\right) \nu_{n, t}+\left(\frac{1}{\phi}\right) \varepsilon_{t},
\end{aligned}
$$

where $i_{n, t}^{*}$ is member $n$ 's preferred interest rate.

Given the economy parameters and private-sector expectations, three empirical implications follow from equation (6). First, committee members agree on their policy reaction to the expected output gap and demand shocks. To see this, note that the coefficients of $E_{t}\left(x_{t+1}-x_{t+1}^{*}\right)$ and $\varepsilon_{t}$ are both equal to $1 / \phi$, which is the inverse of the slope of the IS curve. Second, committee members disagree in their reaction to expected inflation and supply shocks. This follows from the observation that the coefficients of $E_{t} \pi_{t+1}$ and $\eta_{t}$ depend on the idiosyncratic preference parameter $\alpha_{n}$. Finally, even if

\footnotetext{
${ }^{2}$ The model is solved under discretion because the view taken here is that inflation targeting, as it is actually practiced in the United Kingdom and other countries, is not a rule in the classical sense. Bernanke and Mishkin (1997) argue that "inflation targeting ... contains a considerable degree of what most economists would define as policy discretion."
} 
members share the same inflation target and estimate of the natural rate (meaning that $\pi_{n, t}^{*}=\pi_{t}^{*}$ and $\nu_{n, t}=\nu_{t}$ for all $n$ ), they would disagree in their preferred interest rate because the coefficients of $\pi_{n, t}^{*}$ and $\nu_{n, t}$ also depend on $\alpha_{n}$.

The reason why members agree in their response to demand shocks but disagree in their response to supply shocks is the following. In the New Keynesian model, the effect of demand shocks on the output gap may be offset directly by changes in the nominal interest rate (see equation (3)). However, offsetting the effect of supply shocks on inflation requires a monetary-policy-induced change in the output gap; consequently, committee members face a trade-off between inflation and output stabilization.

\section{Empirical Analysis}

\subsection{Data}

The voting data consist of the preferred interest rates stated by each member of the Monetary Policy Committee of the Bank of England in all the meetings held between June 1997 and June 2006. The sample starts with the first meeting of the MPC and ends at the time the data was collected. We use both assenting and dissenting votes. This is possible because the minutes record the names of members in favor of the Governor's proposal and the names and preferred policy options of dissenting members. If a member assents, we attribute to that member the policy adopted by the committee. If a member dissents, we attribute to that member his or her declared policy preference as stated in the minutes. ${ }^{3}$ The underlying assumption is that committee members cast their votes sincerely.

The MPC consists of nine members, of which five are internal (that is, chosen from within the ranks of bank staff) and four are

\footnotetext{
${ }^{3}$ In this sense, we treat assents and dissents symmetrically. The same approach is followed in Tootell (1991, 1999). Chappell, McGregor, and Vermilyea (2005) also use all votes but argue that a dissent favoring a move to, say, tighten is "behaviorally different from an assent that concurs with a committee move to tighten." In their empirical specification, dissents only arise when disagreement is sufficiently acute. Recent game-theoretical models of dissent (see Groseclose and Milyo 2006 and Seidmann 2006) point out that the choice of dissenting or assenting may also depend on strategic considerations (for example, on the probability of being pivotal).
} 
external appointees. Internal members are nominated by the Governor, while external members are appointed by the Chancellor. Meetings are chaired by the Governor of the Bank of England and take place monthly, usually on the Wednesday and Thursday after the first Monday of each month. Decisions are made by simple majority on a one-person, one-vote basis. As of June 2006, twenty-four individuals have been members of the MPC, but six of them have voting records that are too short to allow meaningful empirical analysis. ${ }^{4}$ After excluding these individuals, the sample reduces to 901 votes stated by eighteen MPC members during 109 meetings. $^{5}$

For the estimation of reaction functions, we also use the time series of inflation, unemployment, industrial production, and money growth. Monthly observations of the Retail Price Index (RPI), the Retail Price Index excluding mortgage-interest payments (RPIX), the Consumer Price Index (CPI), the unemployment rate, and the Index of Industrial Production (IIP) were taken from the web site of the UK National Statistics (www.statistics.gov.uk). The stock of money is measured by the end-of-month value of outstanding M4 and was taken from the web site of the Bank of England (www.bankofengland.co.uk).

\subsection{Econometric Strategy}

The reaction function of member $n$ may be written in reduced form as

$$
i_{n, t}=a_{n}+b_{n} E_{t} \pi_{t+1}+c_{n} E_{t}\left(x_{t+1}-x_{t+1}^{*}\right)+w_{n, t},
$$

\footnotetext{
${ }^{4}$ Of these six, four are very recent members of the MPC and, as of June 2006, had participated in only twelve (D. Walton), eight (J. Gieve), four (D. Blanchflower), and one (T. Besley) meetings. H. Davies was a member in the original MPC committee but participated in only two meetings on June 6 and July 10, 1997. A. Budd was a member from December 1997 to May 1999, but his voting record consists of only fourteen observations.

${ }^{5}$ Prior to November 1998, minutes reported whether dissenting members favored tighter or looser policy, but not the interest rates they voted for. This means that a total of twenty-three dissenting votes from the period June 1997 to October 1998 could not be used for the estimation of the individual reaction functions of five members. They are M. King (three votes), A. Budd (four votes), W. Buiter (eight votes), C. Goodhart (three votes), and D. Julius (five votes). Except for W. Buiter, the number of missing observations is relatively small compared with the total number of individual observations.
} 
where

$$
\begin{aligned}
a_{n} & =-\left(\frac{\lambda}{\phi\left(\alpha_{n}+\lambda^{2}\right)}\right) \pi_{t}^{*}, \\
b_{n} & =1+\frac{\lambda \beta}{\phi\left(\alpha_{n}+\lambda^{2}\right)} \\
c_{n} & =\frac{1}{\phi} \\
w_{n, t} & =\left(\frac{\lambda}{\phi\left(\alpha_{n}+\lambda^{2}\right)}\right) \eta_{t}+\left(\frac{\alpha_{n}}{\phi\left(\alpha_{n}+\lambda^{2}\right)}\right) \nu_{n, t}+\left(\frac{1}{\phi}\right) \varepsilon_{t} .
\end{aligned}
$$

Since the Bank of England follows an inflation-targeting policy, the definition of the intercept, $a$, explicitly assumes that committee members share the same inflation target. However, notice that because $a$ also depends on the preference parameter, $\alpha_{n}$, the intercept in the reaction function is member specific. For the same reason, the inflation coefficient, $b$, and the variance of the disturbance term are member specific as well. In principle, the output coefficient, $c$, should be the same for all members, but the approach that we will follow here is to estimate an unrestricted version of the reaction function that allows $c$ to vary across members and then statistically test whether $c$ is constant or not. Following most of the literature, lagged realizations of the interest rate are added to the right-hand side of (7) in order to capture interest-rate smoothing and the serial correlation of the error term. ${ }^{6}$

The assumption of rational expectations on the part of the public means that

$$
\begin{aligned}
\pi_{t+1} & =E_{t} \pi_{t+1}+\zeta_{t+1}, \\
x_{t+1}-x_{t+1}^{*} & =E_{t}\left(x_{t+1}-x_{t+1}^{*}\right)+\xi_{t+1},
\end{aligned}
$$

${ }^{6}$ An alternative approach would be to explicitly incorporate an interest-ratesmoothing motive in the payoff function (1), as in Woodford (2003). However, this strategy makes the model more difficult to solve because the committee member's problem becomes dynamic and its optimal solution requires him or her to forecast the preferred policies of other members. 
where $\zeta_{t+1}$ and $\xi_{t+1}$ are forecast errors uncorrelated with information available at time $t$. Then, substituting (8) and (9) into (7) delivers

$$
i_{n, t}=a_{n}+b_{n} \pi_{t+1}+c_{n}\left(x_{t+1}-x_{t+1}^{*}\right)+u_{n, t},
$$

where the reduced-form disturbance $u_{n, t}=w_{n, t}-b_{n} \zeta_{t+1}-c_{n} \xi_{t+1}$ now includes the forecast errors. Since $\pi_{t+1}$ and $x_{t+1}-x_{t+1}^{*}$ are respectively correlated with $\zeta_{t+1}$ and $\xi_{t+1}$, and hence with $u_{n, t}$, ordinary least squares (OLS) would yield biased and inconsistent parameter estimates. For this reason, we use instead an instrumentalvariables (IV) procedure to estimate the reaction function of each member and of the committee as a whole. In particular, we use efficient generalized method of moments (GMM). As it is well known, GMM is statistically more efficient than the standard IV and twostage least squares (2SLS) because it exploits the heteroskedasticity and serial correlation of the residuals in an initial 2SLS regression to construct the optimal weighting matrix. ${ }^{7}$ We construct the weighting matrix using the Newey-West estimator with a Barlett kernel.

Instruments are the inflation target; one lag of the nominal interest rate, RPI, CPI, and RPIX inflation rates; the rate of money growth; the unemployment rate; and the IIP, the latter two detrended in the manner described below. (We use a one-period lag because publication delays mean that contemporaneous observations may not actually form part of the public's information set at time $t$.) These instruments are both valid and relevant. The instruments are valid because, as part of the public's information set at time $t$, they are uncorrelated with the forecasts errors $\zeta_{t+1}$ and $\xi_{t+1}$, and are uncorrelated with the structural shocks in $w_{n, t}$ because the latter are exogenous by assumption. This means that the instruments are uncorrelated with the error term, $u_{n, t}$. The instruments are relevant because

\footnotetext{
${ }^{7}$ Since the dependent variable is discrete, an alternative strategy would be to use a logit or probit regression. We abstained from following that approach because addressing the endogeneity of expectations is much more difficult in that setup.
} 
they are strongly correlated with the variables they are meant to instrument for. ${ }^{8}$

In the reaction function, inflation is measured by the annual percentage change in the RPIX, ${ }^{9}$ and the output gap is measured by the deviation of the unemployment rate from a Hodrick-Prescott trend computed recursively using a window of 120 observations. ${ }^{10}$ The change in the inflation target is modeled by allowing a break in the intercept term after December 2003, but in order to preserve degrees of freedom, we restrict the size of the break to be equal to the actual target change.

\subsection{Results}

Table 1 reports benchmark results based on a forecast horizon of twelve months. This horizon is motivated by the observation that monetary policy affects output and inflation with a long lag. ${ }^{11}$ Tables 2 and 3 report results using other forecast horizons - namely, nine months (table 2) and six months (table 3). These two tables

\footnotetext{
${ }^{8}$ The $R^{2}$ s for the first-stage regressions vary from 0.66 to 0.92 .

${ }^{9}$ Prior to December 10, 2003, the inflation target applied to the twelve-month change in the RPIX. Thereafter, it applies to the change in the CPI. Results using the RPIX for the sample until December 2003 and the CPI after that are similar to the ones reported below and support the same conclusions, but they unfortunately require a specific assumption as to when the public switched from forecasting RPIX to forecasting CPI inflation.

${ }^{10}$ We also considered using other output measures, but few are available at the monthly frequency. The National Institute for Economic and Social Research produces a monthly GDP index dating back to April 1984, but the series before and after April 1995 are not comparable. The Bank of England compiles an index of capacity utilization based on survey data, but it is not available for the complete sample. In preliminary empirical work, we used the detrended IIP as output-gap measure but found the reaction-function coefficients to be statistically equal to zero in almost all cases and frequently of a sign opposite to that predicted by theory. This result is perhaps not surprising, because manufacturing accounts (as of 2003) for only 16 percent of national output and 13 percent of employment in the United Kingdom and, consequently, is a relatively poor proxy for aggregate output.

${ }^{11}$ Batini and Haldane (1999) evaluate the performance of forecast-based monetary policy rules with different forecast horizons and find that the optimal horizon is around four quarters.
} 
Table 1. Benchmark Results (Twelve-Month Horizon)

\begin{tabular}{|c|c|c|c|c|c|c|c|}
\hline \multicolumn{8}{|c|}{ A. Reaction-Function Coefficients } \\
\hline \multirow[b]{2}{*}{ Member } & \multicolumn{2}{|c|}{ Intercept } & \multicolumn{2}{|c|}{ Inflation } & \multicolumn{2}{|c|}{ Unemployment } & \multirow{2}{*}{$\begin{array}{c}J \text {-test } \\
(p \text {-value })\end{array}$} \\
\hline & Estimate & s.e. & Estimate & s.e. & Estimate & s.e. & \\
\hline George & \multirow{2}{*}{$\begin{array}{l}-0.493 \\
-1.132^{\dagger}\end{array}$} & 0.338 & 0.277 & 0.280 & -0.983 & 0.667 & 0.451 \\
\hline King & & 0.686 & 0.768 & 0.505 & $-2.334^{\dagger}$ & 1.410 & 0.633 \\
\hline Lomax & $-0.233^{*}$ & 0.063 & $0.199 *$ & 0.059 & $-0.661^{*}$ & 0.215 & 0.738 \\
\hline Large & $-0.294^{*}$ & 0.117 & $0.305^{*}$ & 0.137 & -0.407 & 0.472 & 0.433 \\
\hline Tucker & -0.151 & 0.099 & 0.049 & 0.066 & -0.129 & 0.300 & 0.382 \\
\hline Bean & -0.263 & 0.201 & 0.096 & 0.078 & -0.607 & 0.553 & 0.150 \\
\hline Barker & $-0.442^{*}$ & 0.213 & $0.182^{*}$ & 0.092 & -0.692 & 0.600 & 0.429 \\
\hline Nickell & $-0.627^{*}$ & 0.260 & $0.225^{\dagger}$ & 0.131 & $-1.124^{\dagger}$ & 0.603 & 0.517 \\
\hline Allsopp & $-0.657^{*}$ & 0.147 & $0.306^{*}$ & 0.095 & -0.641 & 0.436 & 0.477 \\
\hline Bell & $-0.424^{*}$ & 0.132 & $0.138^{\dagger}$ & 0.074 & $-0.840^{*}$ & 0.281 & 0.567 \\
\hline Lambert & $-0.251^{*}$ & 0.083 & $0.179^{*}$ & 0.060 & $-0.642^{*}$ & 0.221 & 0.627 \\
\hline Buiter & $-1.114^{*}$ & 0.389 & $0.996^{*}$ & 0.357 & $-2.592^{*}$ & 1.095 & 0.152 \\
\hline Goodhart & -0.055 & 0.298 & 0.166 & 0.250 & 0.003 & 0.651 & 0.292 \\
\hline Vickers & $-0.971^{*}$ & 0.236 & $1.088^{*}$ & 0.319 & $-2.246^{*}$ & 0.689 & 0.478 \\
\hline Julius & $-1.281^{*}$ & 0.335 & $1.278^{*}$ & 0.403 & $-2.381^{*}$ & 0.531 & 0.546 \\
\hline Wadhwani & -0.262 & 0.236 & 0.036 & 0.129 & $-1.391^{*}$ & 0.308 & 0.524 \\
\hline Plenderleith & $-1.394^{\dagger}$ & 0.788 & 1.185 & 0.755 & -2.113 & $\begin{array}{l}0.000 \\
1.368\end{array}$ & 0.932 \\
\hline Clementi & $-0.656^{\dagger}$ & 0.368 & 0.448 & 0.308 & -0.871 & $\begin{array}{l}1.000 \\
0.817\end{array}$ & 0.524 \\
\hline Committee & -0.927 & 0.628 & 0.630 & 0.467 & -1.808 & 1.308 & 0.576 \\
\hline B. Inc & lividual an & d Com & mittee Coe & efficient & s Are Equ & $(p$-va & lue) \\
\hline & & tercept & & nflation & & nemplo & yment \\
\hline All Members & & 0.002 & & 0.003 & & 0.0 & \\
\hline External & & 0.020 & & 0.034 & & 0.0 & \\
\hline Internal & & 0.050 & & 0.170 & & 0.2 & \\
\hline Academic & & 0.262 & & 0.055 & & 0.5 & \\
\hline Private & & 0.117 & & 0.260 & & 0.0 & \\
\hline Bank & & 0.419 & & 0.248 & & 0.3 & \\
\hline & & C. I & Median Co & efficien & & & \\
\hline & & tercept & & nflation & & nemplo & yment \\
\hline All Members & & -0.468 & & 0.251 & & -0.8 & \\
\hline External & & -0.442 & & 0.182 & & -0.8 & \\
\hline Internal & & -0.493 & & 0.305 & & -0.8 & \\
\hline Academic & & -0.814 & & 0.537 & & -1.6 & \\
\hline Private & & -0.424 & & 0.182 & & -0.8 & \\
\hline Bank & & -0.233 & & 0.199 & & -0.6 & \\
\hline
\end{tabular}




\section{Table 1. (Continued)}

\begin{tabular}{|c|c|c|}
\hline \multicolumn{3}{|c|}{ D. Committee Coefficients Are Equal to the Median ( $p$-value) } \\
\hline Intercept & Inflation & Unemployment \\
\hline 0.464 & 0.418 & 0.467 \\
\hline \multicolumn{3}{|c|}{$\begin{array}{l}\text { Note: Internal members are George, King, Lomax, Large, Tucker, Bean, Vickers, } \\
\text { Plenderleith, and Clementi. The remaining members are external. King, Bean, } \\
\text { Nickell, Allsopp, Buiter, and Vickers have academic background. Large, Barker, Bell, } \\
\text { Lambert, Julius, and Clementi come from the private sector. The remaining mem- } \\
\text { bers have been Bank of England staff or government officials. See Spencer }(2006) \\
\text { for additional details. The superscripts }{ }^{*} \text { and }{ }^{\dagger} \text { denote the rejection of the null } \\
\text { hypothesis that true coefficient is zero at the } 5 \text { percent and } 10 \text { percent significance } \\
\text { levels. }\end{array}$} \\
\hline
\end{tabular}

Table 2. Robustness to Forecast Horizon (Nine-Month Horizon)

\begin{tabular}{|l|l|l|l|l|l|l|l|}
\hline \multicolumn{7}{|c|}{ A. Reaction-Function Coefficients } \\
\hline \multirow{2}{*}{ Member } & Intercept & \multicolumn{2}{|c|}{ Inflation } & \multicolumn{2}{c|}{ Unemployment } & \multirow{2}{*}{ J-test } \\
\cline { 2 - 7 } & Estimate & s.e. & Estimate & s.e. & Estimate & s.e. & -value $)$ \\
\hline George & -0.182 & 0.127 & 0.081 & 0.116 & $-0.621^{*}$ & 0.279 & 0.357 \\
King & $-0.348^{*}$ & 0.156 & $0.237^{\dagger}$ & 0.130 & $-0.888^{*}$ & 0.334 & 0.347 \\
Lomax & -0.096 & 0.075 & 0.137 & 0.111 & $-0.301^{*}$ & 0.127 & 0.307 \\
Large & -0.067 & 0.109 & -0.053 & 0.098 & -0.104 & 0.201 & 0.381 \\
Tucker & -0.017 & 0.100 & -0.075 & 0.064 & -0.078 & 0.200 & 0.573 \\
Bean & $-0.256^{*}$ & 0.100 & $0.181^{*}$ & 0.072 & $-0.685^{*}$ & 0.272 & 0.649 \\
Barker & $-0.289^{*}$ & 0.118 & 0.167 & 0.124 & $-0.555^{\dagger}$ & 0.324 & 0.497 \\
Nickell & $-0.336^{*}$ & 0.116 & $0.175^{\dagger}$ & 0.103 & $-0.785^{*}$ & 0.286 & 0.476 \\
Allsopp & $-0.645^{*}$ & 0.093 & $0.410^{*}$ & 0.083 & 0.317 & 0.268 & 0.378 \\
Bell & $-0.289^{*}$ & 0.129 & 0.067 & 0.095 & $-0.716^{*}$ & 0.334 & 0.235 \\
Lambert & -0.081 & 0.089 & -0.043 & 0.149 & $-0.403^{*}$ & 0.129 & 0.338 \\
Buiter & $-0.365^{*}$ & 0.178 & 0.128 & 0.207 & $-2.076^{*}$ & 0.729 & 0.420 \\
Goodhart & -0.216 & 0.136 & $0.224^{*}$ & 0.110 & -0.712 & 0.445 & 0.266 \\
Vickers & -0.365 & 0.242 & 0.386 & 0.287 & $-1.288^{*}$ & 0.410 & 0.334 \\
Julius & $-0.390^{*}$ & 0.173 & 0.312 & 0.248 & $-1.176^{*}$ & 0.400 & 0.334 \\
Wadhwani & -0.245 & 0.185 & 0.169 & 0.138 & $-1.140^{*}$ & 0.203 & 0.186 \\
Plenderleith & $-0.265^{*}$ & 0.127 & 0.229 & 0.165 & $-0.717^{*}$ & 0.267 & 0.360 \\
Clementi & $-0.346^{\dagger}$ & 0.192 & 0.248 & 0.204 & $-0.974^{\dagger}$ & 0.527 & 0.517 \\
Committee & $-0.445^{*}$ & 0.185 & $0.320^{*}$ & 0.148 & $-1.000^{*}$ & 0.382 & 0.594 \\
\hline
\end{tabular}




\section{Table 2. (Continued)}

\begin{tabular}{|c|c|c|c|}
\hline \multicolumn{4}{|c|}{ B. Individual and Committee Coefficients Are Equal ( $p$-value) } \\
\hline & Intercept & Inflation & Unemployment \\
\hline All Members & 0.004 & 0.031 & $<0.001$ \\
\hline External & 0.013 & 0.057 & 0.002 \\
\hline Internal & 0.306 & 0.812 & 0.048 \\
\hline Academic & 0.150 & 0.007 & 0.007 \\
\hline Private & 0.342 & 0.909 & 0.012 \\
\hline Bank & 0.308 & 0.435 & 0.159 \\
\hline \multicolumn{4}{|c|}{ C. Median Coefficients } \\
\hline & Intercept & Inflation & Unemployment \\
\hline All Members & -0.277 & 0.172 & -0.714 \\
\hline External & -0.289 & 0.169 & -0.716 \\
\hline Internal & -0.256 & 0.181 & -0.685 \\
\hline Academic & -0.356 & 0.209 & -0.836 \\
\hline Private & -0.289 & 0.167 & -0.716 \\
\hline Bank & -0.182 & 0.137 & -0.621 \\
\hline \multicolumn{4}{|c|}{ D. Committee Coefficients Are Equal to the Median ( $p$-value) } \\
\hline & Intercept & Inflation & Unemployment \\
\hline & 0.363 & 0.317 & 0.454 \\
\hline \multicolumn{4}{|c|}{$\begin{array}{l}\text { Note: Internal members are George, King, Lomax, Large, Tucker, Bean, Vickers, } \\
\text { Plenderleith, and Clementi. The remaining members are external. King, Bean, } \\
\text { Nickell, Allsopp, Buiter, and Vickers have academic background. Large, Barker, Bell } \\
\text { Lambert, Julius, and Clementi come from the private sector. The remaining members } \\
\text { have been Bank of England staff or government officials. See Spencer (2006) for addi- } \\
\text { tional details. The superscripts }{ }^{*} \text { and }{ }^{\dagger} \text { denote the rejection of the null hypothesis } \\
\text { that the true coefficient is zero at the } 5 \text { percent and } 10 \text { percent significance levels. }\end{array}$} \\
\hline
\end{tabular}

serve to assess the robustness of the results to different forecast horizons. ${ }^{12}$

Panel A in table 1 reports estimates of individual and committee reaction functions. These results indicate that the voting behavior

\footnotetext{
${ }^{12}$ The working paper version of this article (Riboni and Ruge-Murcia 2007) reports results using a different measure of inflation-namely, RPI inflation. Those results are very similar to the ones reported here and indicate that our conclusions are also robust to the index used to compute inflation.
} 
Table 3. Robustness to Forecast Horizon
(Six-Month Horizon)

\begin{tabular}{|l|c|c|c|c|c|c|c|}
\hline \multicolumn{7}{|c|}{ A. Reaction-Function Coefficients } \\
\hline \multirow{2}{*}{ Member } & Intercept & \multicolumn{2}{c|}{ Inflation } & \multicolumn{2}{c|}{ Unemployment } & \multirow{2}{*}{-test } \\
\cline { 2 - 7 } & Estimate & s.e. & Estimate & s.e. & Estimate & s.e. & (p-value) \\
\hline George & $-0.171^{\dagger}$ & 0.099 & 0.119 & 0.098 & -0.244 & 0.203 & 0.195 \\
King & -0.125 & 0.082 & 0.101 & 0.076 & $-0.396^{*}$ & 0.176 & 0.168 \\
Lomax & -0.001 & 0.050 & 0.013 & 0.041 & $-0.168^{\dagger}$ & 0.100 & 0.276 \\
Large & 0.118 & 0.082 & $-0.207^{*}$ & 0.089 & -0.076 & 0.172 & 0.560 \\
Tucker & 0.052 & 0.087 & $-0.127^{\dagger}$ & 0.077 & -0.069 & 0.169 & 0.547 \\
Bean & -0.079 & 0.066 & $0.123^{*}$ & 0.050 & -0.163 & 0.144 & 0.577 \\
Barker & -0.078 & 0.067 & 0.039 & 0.053 & -0.143 & 0.146 & 0.347 \\
Nickell & -0.140 & 0.089 & 0.037 & 0.069 & $-0.372^{*}$ & 0.166 & 0.576 \\
Allsopp & $-0.339^{\dagger}$ & 0.195 & 0.110 & 0.147 & 0.008 & 0.357 & 0.122 \\
Bell & -0.188 & 0.165 & 0.110 & 0.139 & -0.386 & 0.319 & 0.162 \\
Lambert & -0.041 & 0.070 & 0.026 & 0.079 & -0.169 & 0.129 & 0.433 \\
Buiter & 0.082 & 0.182 & $0.549^{*}$ & 0.275 & $-1.735^{*}$ & 0.500 & 0.325 \\
Goodhart & -0.055 & 0.104 & 0.276 & 0.197 & $-0.701^{*}$ & 0.246 & 0.342 \\
Vickers & -0.366 & 0.304 & 0.581 & 0.374 & $-1.683^{*}$ & 0.567 & 0.328 \\
Julius & $-0.341^{\dagger}$ & 0.205 & $0.597^{*}$ & 0.166 & $-2.197^{*}$ & 0.443 & 0.480 \\
Wadhwani & 0.233 & 0.142 & 0.186 & 0.177 & $-2.026^{*}$ & 0.350 & 0.715 \\
Plenderleith & -0.140 & 0.099 & $0.304^{\dagger}$ & 0.185 & $-0.670^{*}$ & 0.315 & 0.132 \\
Clementi & $-0.205^{\dagger}$ & 0.122 & $0.283^{\dagger}$ & 0.172 & $-0.921^{*}$ & 0.388 & 0.165 \\
Committee & $-0.201^{*}$ & 0.084 & $0.164^{*}$ & 0.072 & $-0.377^{*}$ & 0.158 & 0.220 \\
\hline
\end{tabular}

B. Individual and Committee Coefficients Are Equal ( $p$-value)

\begin{tabular}{|l|c|c|c|}
\hline & Intercept & Inflation & Unemployment \\
\hline All Members & 0.100 & $<0.001$ & $<0.001$ \\
External & 0.199 & $<0.001$ & $<0.001$ \\
Internal & 0.073 & 0.324 & 0.114 \\
Academic & 0.618 & $<0.001$ & 0.085 \\
Private & 0.026 & 0.040 & $<0.001$ \\
Bank & 0.165 & 0.182 & 0.382 \\
\hline
\end{tabular}

C. Median Coefficients

\begin{tabular}{|l|c|c|c|}
\hline & Intercept & Inflation & Unemployment \\
\hline All Members & -0.102 & 0.114 & -0.379 \\
External & -0.078 & 0.110 & -0.386 \\
Internal & -0.125 & 0.119 & -0.244 \\
Academic & -0.132 & 0.116 & -0.384 \\
Private & -0.078 & 0.110 & -0.386 \\
Bank & -0.055 & 0.119 & -0.244 \\
\hline
\end{tabular}




\section{Table 3. (Continued)}

\begin{tabular}{|l|c|c|c|}
\hline \multicolumn{4}{|c|}{ D. Committee Coefficients Are Equal to the Median (p-value) } \\
\hline & Intercept & Inflation & Unemployment \\
\hline & 0.236 & 0.490 & 0.994 \\
\hline $\begin{array}{l}\text { Note: Internal members are George, King, Lomax, Large, Tucker, Bean, Vickers, } \\
\text { Plenderleith, and Clementi. The remaining members are external. King, Bean, } \\
\text { Nickell, Allsopp, Buiter, and Vickers have academic background. Large, Barker, Bell, } \\
\text { Lambert, Julius, and Clementi come from the private sector. The remaining members } \\
\text { have been Bank of England staff or government officials. See Spencer (2006) for addi- } \\
\text { tional details. The superscripts * and }{ }^{\dagger} \text { denote the rejection of the null hypothesis } \\
\text { that the true coefficient is zero at the } 5 \text { percent and } 10 \text { percent significance levels. }\end{array}$ \\
\hline
\end{tabular}

of individual MPC members is generally consistent with the theory. First, point estimates of the inflation (unemployment) coefficients are usually positive (negative) and statistically significant, meaning that members tend to vote to raise (lower) the repo rate when inflation (unemployment) twelve months ahead is expected to increase. In this and other tables, there are occasional exceptions to this general observation, but exceptions are usually characterized by numerically small and statistically insignificant coefficients. Second, the overidentifying restrictions of the model cannot be rejected for any committee member nor for the committee as a whole. To see this, note that the $p$-values of $J$-tests reported in the last column of panel A in table 1 are all above standard significance levels. Comparing these results with those in panel $\mathrm{A}$ in tables 2 and 3 indicates that these conclusions are robust to the forecast horizon. The reaction-function coefficients are also graphically reported in figure 1, where "pluses" are coefficients of internal members, "crosses" are coefficients of the external members, and vertical lines are the coefficients of the committee as a whole. Overall, results in panel A and figure 1 suggest that, in qualitative terms, MPC members are fairly homogeneous in their policy preferences.

However, these results also indicate that, in quantitative terms, the reaction coefficients vary substantially across committee members. In order to examine whether this heterogeneity is statistically significant, we perform Wald tests of the joint null hypothesis that 


\section{Figure 1. Reaction-Function Coefficients}
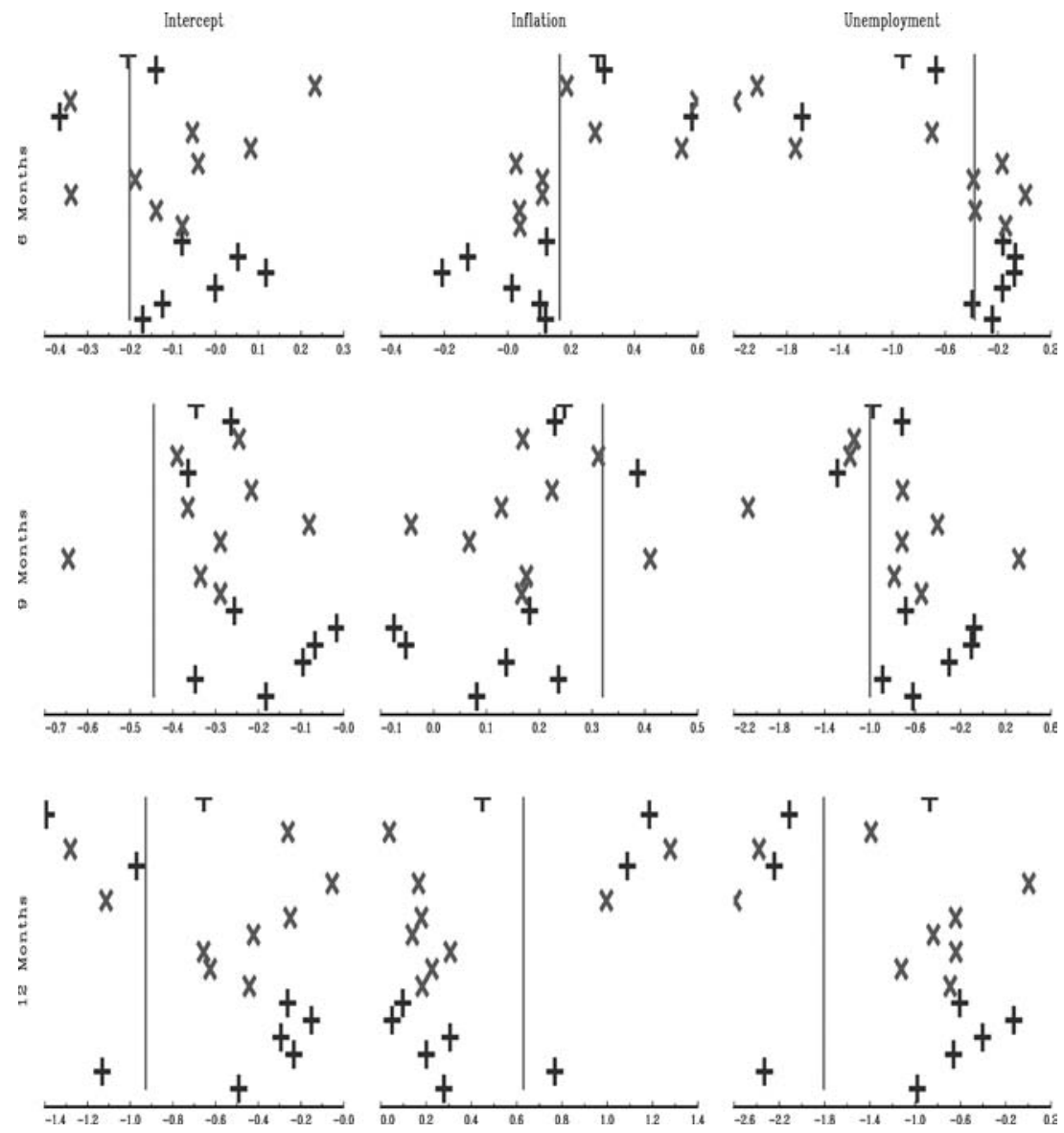

the individual coefficients are equal to those of the committee and report results in panel $\mathrm{B}$ of table 1 . For the complete sample of all committee members, the hypothesis can be rejected at the 5 percent significance level for the intercept and inflation coefficient but not for the unemployment coefficient. Although the latter result is marginal, it is in line with the implication of the model that members are more likely to disagree on their policy reaction to expected inflation than on their reaction to the expected output gap. Recall that in the model this was due to the fact that changes in expected 
inflation require a monetary-policy-induced change in the output gap that leads to a trade-off between inflation and output stabilization, while changes in the expected output gap may be offset directly by adjusting the nominal interest rate. From panel B in tables 2 and 3, it is clear that the rejection of the null hypothesis for the inflation coefficients is robust to the forecast horizon, but results concerning the unemployment coefficient are not. Overall, these statistical results suggest that individual policy responses within the MPC are heterogeneous.

Figure 2 plots the relation between the reaction-function coefficients for all members for all possible pairwise comparisons. In all cases there is a positive and statistically significant relation across forecast horizons. ${ }^{13}$ This means that, in general, individuals who favor a strong response to expected inflation or unemployment do so regardless of the forecast horizons. Thus, the heterogeneity in individual policy responses within the MPC appears to be systematic.

There are at least two dimensions along which MPC members differ systematically. First, the nature of their appointment (whether internal or external to the Bank of England) and, second, their career background (whether academic, private sector, or Bank of England). ${ }^{14}$ Thus, we also perform the Wald test described above for subsamples of committee members. These results are reported in panel B of table 1 and show that the hypothesis that the individual inflation and unemployment coefficients are equal to those of the committee cannot be rejected for internal and Bank members, but is frequently rejected for external, academic, and private-sector members. ${ }^{15}$ These results are not independent, because most academic and private-sector members in the MPC are also external appointees, while Bank members are internal members. Results are generally robust to the forecast horizon (see panel B in tables 2 and 3) and, as a whole, statistically confirm the idea that one important source of heterogeneity within the MPC is the nature of the

\footnotetext{
${ }^{13}$ To save space, the slope parameters are not reported, but their $t$-statistics range from 2.21 to 5.27 .

${ }^{14}$ For the classification of MPC members in terms of career background, we mostly rely on the information contained in Spencer (2006).

${ }^{15}$ Note, however, that in some cases results are marginal in that the hypothesis would be rejected at the 5 percent but not the 10 percent significance level.
} 


\section{Figure 2. Relation Between Coefficients at Different Horizons}
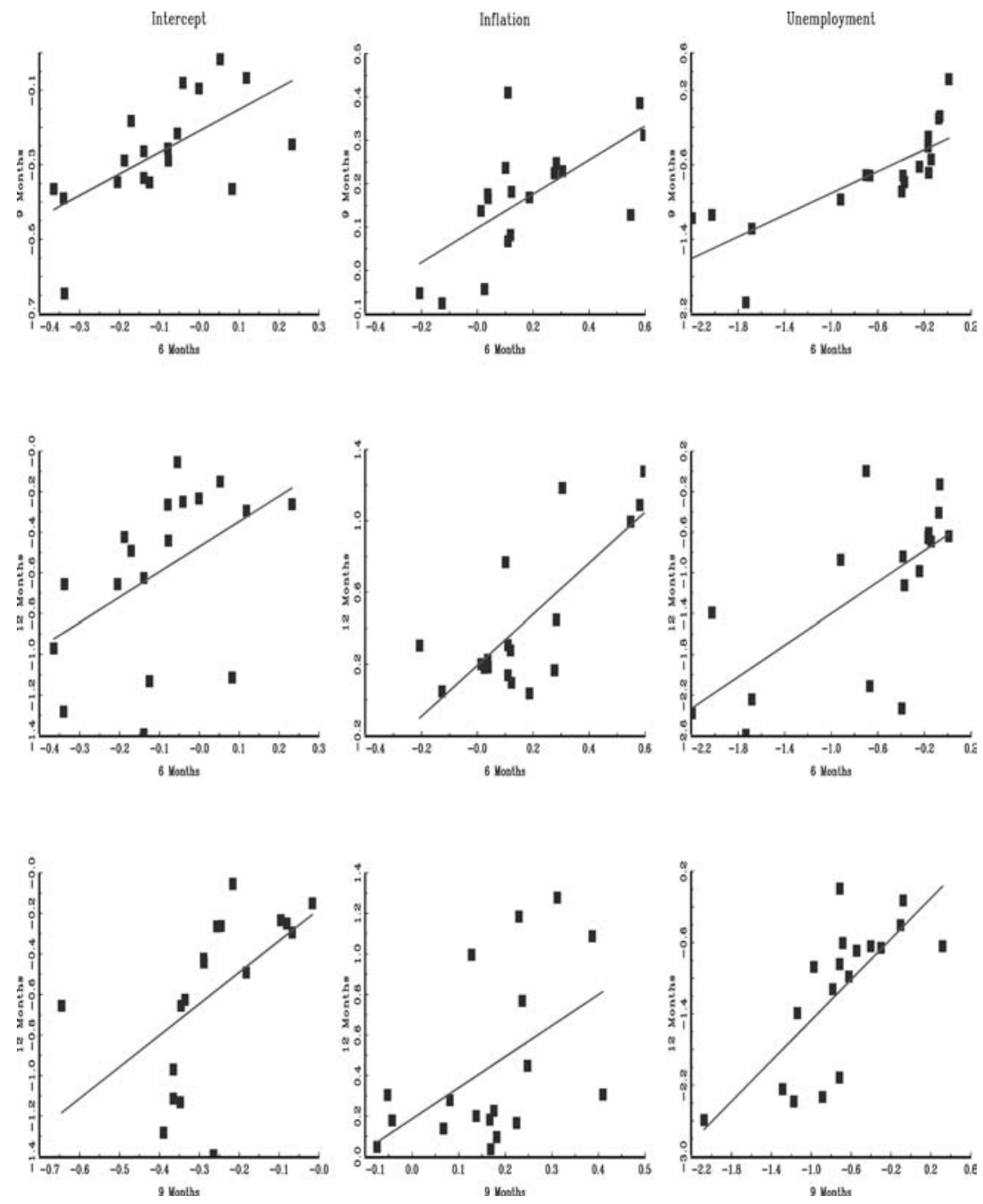

individual membership. ${ }^{16}$ In order to further explore this finding, panel $\mathrm{C}$ in tables $1-3$ reports the median coefficients for all members and subsamples. Estimates indicate that the median external

\footnotetext{
${ }^{16}$ On this point, see also Gerlach-Kristen (2003) and Spencer (2006).
} 
member tends to react more strongly to unemployment than the median internal member, but there is no clear pattern regarding their reaction to inflation. The same result is observed when comparing academic and private-sector members with Bank members. In general, reaction-function coefficients increase with the forecast horizon, especially for academics.

Finally, panel D in table 1 reports the results of $t$-tests that the committee reaction-function coefficients are equal to the median of the individual coefficients. Since the $p$-values are above standard significance levels, the hypothesis cannot be rejected for the intercept, inflation, or unemployment. From panel D in tables 2 and 3, it is clear that this result is robust to the forecast horizon. Since the committee and median coefficients are (statistically) the same but the coefficients of committee and external members are (statistically) different, it follows that the median voter in the MPC is likely be an internal member.

\section{Conclusions}

This paper exploits the voting records of the Monetary Policy Committee of the Bank of England to study preference heterogeneity among committee members. The analysis is motivated by the empirical observations that disagreement is frequent within the MPC and by summary statistics reported in earlier literature that suggest differences in voting patterns. This research shows that, in qualitative terms, MPC members are fairly homogeneous in their policy preferences. That is, individual members tend to vote for an interest rate raise (decrease) when inflation (unemployment) is expected to increase, as one would expect. However, there are systematic quantitative differences in their policy reaction functions that appear related to the nature of the membership and previous career background. These systematic differences may be important in the decision-making process of the MPC and affect the interest rate level selected by the committee.

\section{References}

Batini, N., and A. Haldane. 1999. "Monetary Policy Rules and Inflation Forecasts." Quarterly Bulletin (Bank of England) 39: 60-67. 
Belden, S. 1989. "Policy Preferences of FOMC Members as Revealed by Dissenting Votes." Journal of Money, Credit, and Banking 21 (4): 432-41.

Bernanke, B. S., and F. S. Mishkin. 1997. "Inflation Targeting: A New Framework for Monetary Policy?" Journal of Economic Perspectives 11 (2): 97-116.

Chappell, H. W., R. R. McGregor, and T. Vermilyea. 2005. Committee Decisions on Monetary Policy. Cambridge, MA: MIT Press.

Fry, M., D. Julius, L. Mahadeva, S. Roger, and G. Sterne. 2000. "Key Issues in the Choice of Monetary Policy Framework." In Monetary Frameworks in a Global Context, ed. L. Mahadeva and G. Sterne. London: Routledge.

Gerlach-Kristen, P. 2003. "Insiders and Outsiders at the Bank of England." Central Banking 14: 96-102.

Gildea, J. A. 1990. "Explaining FOMC Members' Votes." In The Political Economy of American Monetary Policy, ed. T. Mayer, 211-28. Cambridge: Cambridge University Press.

Groseclose, T., and J. Milyo. 2006. "A Rational-Choice, FormalTheoretic Argument Against the Existence of Sophisticated Voting in Legislatures." Mimeo, University of California, Los Angeles.

Havrilesky, T. M., and J. A. Gildea. 1991. "The Policy Preferences of FOMC Members as Revealed by Dissenting Votes: Comment." Journal of Money, Credit, and Banking 23 (1): 130-38.

Havrilesky, T. M., and R. L. Schweitzer. 1990. "A Theory of FOMC Dissent Voting with Evidence from the Time Series." In The Political Economy of American Monetary Policy, ed. T. Mayer, 197-210. Cambridge: Cambridge University Press.

McCallum, B. T., and E. Nelson. 1999. "An Optimizing IS-LM Specification for Monetary Policy and Business Cycle Analysis." Journal of Money, Credit, and Banking 31 (3): 296-316.

Meade, E. E., and D. N. Sheets. 2005. "Regional Influences on FOMC Voting Patterns." Journal of Money, Credit, and Banking 37 (4): 661-77.

Riboni, A., and F. J. Ruge-Murcia. 2007. "Preference Heterogeneity in Monetary Policy Committees." DNB Working Paper No. 157. Seidmann, D. 2006. "A Theory of Voting Patterns and Performance in Private and Public Committees." Mimeo, Nottingham University. 
Spencer, C. 2006. "The Dissent Voting Bahaviour of Bank of England MPC Members." Discussion Paper 03/06, University of Surrey.

Tootell, G. M. B. 1991. "Are District Presidents More Conservative than Board Governors?" New England Economic Review (Federal Reserve Bank of Boston), 3-12.

- 1999. "Whose Monetary Policy Is It Anyway?" Journal of Monetary Economics 43 (1): 217-35.

Woodford, M. 2003. "Optimal Interest-Rate Smoothing." Review of Economic Studies 70 (4): 861-86. 